\title{
Synthesis and Anticancer Activity of Triazole Linked Macrocycles and Heterocycles
}

\author{
Avula Srinivas ${ }^{1, *}$ and Enugala Kalyan Rao $^{2}$ \\ ${ }^{1}$ Department of Chemistry, Vaagdevi Degree \& $P G$ College Kishanpura, Warangal, Telangana, India 506001 \\ ${ }^{2}$ Department of Physical Sciences, Kakatiya Institute of Technological Sciences Warangal, Telangana, \\ India 506015
}

*Corresponding author: E-mail: avula.sathwikreddy@gmail.com

Received: $10-23-2020$

\begin{abstract}
Synthesis of macrocylic enones starting from alkyl ether and triazole as a linker was achieved using click reaction and intramolecular aldol condensation. The newly synthesized macrocyclic enone was successfully utilized as a dipolarophile in 1,3-dipolar cycloaddition. The dipoles generated from hydrazine hydrochloride, hydroxylamine and guanidine hydrochloride were reacted with macrocyclic enone to give a new class of spiro aminopyrimidines, phenyl pyrazoles and isoxazoles grafted macrocycles in good yield. The structures of newly synthesized compounds were confirmed with IR, NMR and mass spectroscopy and evaluated for their anti cancer activity.
\end{abstract}

Keywords: Triazoles; click reaction; internal aldol condensation; macrocyclic enones; anticancer activity

\section{Introduction}

Carbohydrates are most important class of bio-molecules, their structural components have an important role in biological processes and organic synthesis. ${ }^{1}$ In the chemical, pharmaceutical, food, cosmetic and detergent industries they act as readily available intermediates stocks for large scale applications ${ }^{2}$ and also they have an important role in cell physiology in the form of glycoconjugates (glycolipids, glycoproteins and polysaccharides) and in many biological processes such as intercellular recognisation, bacterial and viral infection, cancer metastasis, apoptosis and neuronal proliferation, etc. ${ }^{3}$ The introduction of a carbohydrate moiety into a system often imparts interesting properties such as hydrophilicity, lowered noxious and escalated bioactivities, ${ }^{4}$ organic chemists have linked carbohydrates to various biologically potent compounds to escalate their biological applications, such as steroids, amino acids and other therapeutic agents. ${ }^{5}$ One of the methods used to link a carbohydrate moiety with a potential compound is via a triazole ring using the well known click-chemistry reaction. ${ }^{6}$ The strategy of linking a carbohydrate moiety with another species via a triazole ring is gaining importance in organic synthesis, natural products chemistry and bio chemistry. ${ }^{7}$ The stability, polar nature and possible hydrogen bonding ability of a triazole ring combined with the biocompatibility and presence of stereogenic centers, the stereogenic centers of a carbohydrate moiety make glucal- based triazoles very interesting for organic synthetic chemists.

Macrocyclic compounds with large cavities are found to have potential application in chemistry, biology and nanotechnology, ${ }^{8,9}$ With potent biological activities, heteroatoms-containing macro cyclic compounds are present in natural products. ${ }^{10}$ Heterocyclic compounds are known to interact with various proteins and heterocyclic units are constituent parts of magnificent molecular ligands $;{ }^{12}$ such compounds can also act as magic eye for chiral molecules and can be used for selective metal ion and anion remembrance. ${ }^{13,14} \mathrm{The} \mathrm{Cu}(\mathrm{I})$-catalyzed alkynes -azide cycloaddition is the most useful modality for the fashioning of diversification of 1,2,3-triazole grafted macrocycles. ${ }^{15}$ In recent years 1,2,3-triazoles have large attraction in supramolecular chemistry because of their dual nature to act as both hydrogen bond donors and acceptors 16,17 due to their firmness and lyomerous properties, these triazoles can be of more conspicuous use as a non-peptide inhibitors. ${ }^{18}$ Furthermore, they exhibit large variety of medical activities. ${ }^{19}$ Triazole glycosides are also present in the structures of various antiviral drugs such as Ribavirin and $\beta$-D-ribofuranosyl-1,2,4-triazole-3-carboxamide. ${ }^{20}$ Isoxazole derivatives are pertinent class of bioactive 
molecules, which express glaring activities such as protein tyrosinephosphatase 1 inhibitors, ${ }^{21}$ antiviral, ${ }^{22}$ antihelmintic, ${ }^{23}$ antiinflammatory, ${ }^{24}$ anticonvulsant, ${ }^{25}$ insecticidal, ${ }^{26}$ antitubercular, ${ }^{27}$ immunomodulatory, ${ }^{28}$ and hypolipermic. ${ }^{29}$ Moreover pyrazoles and their derivatives could be considered as possible antimicrobial agents,${ }^{30}$ activities of the other derivatives include antidepressant, ${ }^{31}$ antiarthritic ${ }^{32}$ and cerebroprotectors. ${ }^{33}$ Some aryl pyrazoles were reported to act as non nucleoside human immunodeficiency virus (HIV-1) reverse transcriptase inhibitors, ${ }^{34} \mathrm{COX}-2$ inhibitors, ${ }^{35-37}$ activators of the nitric oxide receptors and soluble guanylate cyclase activity. ${ }^{38}$ On the other hand, the pyrimidines have special place and have contributed exceptionally to biological and medicinal fields, ${ }^{39}$ with activities such as antitubercular, ${ }^{40}$ and calcium channel blockers, ${ }^{41}$ and also many pyrimidines ${ }^{42}$ have displayed diverse pharmaceutical activities depending upon the geometry and type of substituents attached to the ring. ${ }^{43} 3$-Azido-3-deoxythymidine (AZT) ${ }^{44}$ a pyrimidine derivative, has been found to be an eloquent antiviral agent against HIV type 1 in vitro, and has been found to decrease mortality and opportunistic infections in patients with AIDS.

Following the successful introduction, inspired by the biological profile of triazoles, macrolides, isoxazoles, pyrazoles and pyramidines, and in the continuation of our work on biologically active heterocycles ${ }^{45-52}$ we have developed a series of novel triazole linked furanose pyranose macrocycles, their heterocyclic counterparts and evaluated their anticancer activity.

\section{Results and Discussion}

The key intermediate $\mathbf{8}$ required for the synthesis of compounds 9, 10 and 11 was prepared according to the procedure outlined in the Scheme 1. 1-(2-(4-Bromobutoxy)phenyl)ethanone (2), prepared from 2-hydroxyacetophenone by treating with 1,4-dibromopropane in DMF in the presence of $\mathrm{K}_{2} \mathrm{CO}_{3}$, followed by sodium azide, gave its corresponding azide, is converted into triazole 7 (82\%) by using 1,3-dipolar cycloaddition with propargyl ether $\mathbf{4}$ carried out at ambient temperature in the presence of $\mathrm{CuSO}_{4}$ and sodium ascorbate in a mixture of $1: 1 \mathrm{CH}_{2} \mathrm{Cl}_{2}-$
$\mathrm{H}_{2} \mathrm{O}$. Acid hydrolysis of 5 in $60 \% \mathrm{AcOH}$ furnished the diol 6, which on oxidative cleavage with $\mathrm{NaIO}_{4}$ gave the aldehyde 7, which is subjected to internal aldol condensation to give macrocycle ${ }^{53} \mathbf{8}$ (Scheme 1). Compound 8 was then reacted with hydroxylamine, hydrazine hydrochloride and guanidine hydrochloride at reflux temperature to gave macrocyclic derivatives $\mathbf{9 , 1 0}$ and $\mathbf{1 1}$.

The key intermediate $\mathbf{2 0}$ required for the synthesis of compounds 21, 22 and 23 was prepared according to the procedure outlined in the scheme 2. 1-(2-(4-Bromobutoxy)phenyl)ethanone (2), prepared from 2-hydroxyacetophenone by treating with 1,4-dibromopropane in DMF in the presence of $\mathrm{K}_{2} \mathrm{CO}_{3}$, followed by sodium azide to give its corresponding azide, is converted into triazole 7 (82\%) by using 1,3-dipolar cycloaddition with propargyl ether 16, carried out at ambient temperature in the presence of $\mathrm{CuSO}_{4}$ and sodium ascorbate in a mixture of $1: 1 \mathrm{CH}_{2} \mathrm{Cl}_{2}-$ $\mathrm{H}_{2} \mathrm{O}$, oxidation of compound $\mathbf{1 8}$ with IBX gave aldehyde, which is subjected to internal aldol condensation to give macrocycle ${ }^{53} 20$ (Scheme 2). Compound 20 was then reacted with hydroxylamine, hydrazine hydrochloride and guanidine hydrochloride at reflux temperature to gave macrocyclic derivatives 21, 22 and 23. The structures of synthesized compounds were determined by IR, NMR, MS spectra and evaluated for their anticancer activity.

\section{In vitro Cytotoxicity}

Anticancer activity of the compounds $9, \mathbf{1 0}, \mathbf{1 1}, \mathbf{2 1}$, 22 and 23 was determined on the basis of measurement of in vitro growth inhibition of tumor cell lines in 96 well plates by cell-mediated reduction of tetrazolium salt to the formation of water insoluble crystals using doxorubicin as a standard. The cytotoxicity was assessed against a panel of four different human tumor cell lines: A549 derived from human alveolar adenocarcinoma epithelial cells (ATCC No.CCL-185), HeLa derived from human cervical cancer cells (ATCC No. CCL-2), MDA-MB-231 derived from human breast adenocarcinoma cells (ATCC No. HTB22), MCF-7 (Michigan cancer Foundation cell line) and HEK 293 (normal human embryonic kidney cell line) using the MTT assays. ${ }^{54}$ The $\mathrm{IC}_{50}$ values were calculated

Table 1. In vitro anticancer activity of selected compounds

\begin{tabular}{lccccc}
\hline Compound & A549 & Hela & $\begin{array}{c}\text { IC }_{\text {50 }} \text { values in } \boldsymbol{\mu M} \\
\text { MDAMB231 }\end{array}$ & MCF-7 & HEK 293 \\
\hline 9 & 6.22 & 5.42 & 6.39 & $\mathbf{1 . 8 2}$ & $>100$ \\
10 & 7.02 & 3.92 & 4.01 & 10.07 & $>100$ \\
11 & $>100$ & 3.76 & 4.21 & $>100$ & $>100$ \\
21 & 12.09 & 2.98 & 3.97 & $>100$ & $>100$ \\
22 & $>100$ & 3.56 & 3.75 & 15.99 & $>100$ \\
23 & 6.01 & 5.05 & 6.05 & $\mathbf{1 . 9 0}$ & $>100$ \\
Doxorubicin & $\mathbf{0 . 4 5 9}$ & $\mathbf{0 . 5 0 9}$ & $\mathbf{0 . 9 1}$ & $\mathbf{1 . 0 7}$ & $>100$ \\
\hline
\end{tabular}

Srinivas and Rao: Synthesis and Anticancer Activity ... 
from the plotted absorbance data for the dose-response curves. $\mathrm{IC}_{50}$ values (in $\mu \mathrm{M}$ ) are indicated as mean $\pm \mathrm{SD}$ of three independent experiments. From the data reported in Table 1, most of the prepared compounds possessed significant cytotoxicity effect on all the tested cell lines and potencies of some of the compounds were comparable to the standard doxorubicin, the most widely used drug for the treatment of tumors. Among the tested compounds 9 and 23 showed the most potent activity against MCF-7 cell line with $\mathrm{IC}_{50}$ value of 1.82 and $1.90 \mu \mathrm{M}$, whereas $\mathbf{1 0}$, 11, 21 and 22 showed promising activity against MDAMB-231 and HeLa cell lines.

\section{Experimental}

Commercial grade reagents were used as supplied, solvents (except those of analytical reagent grade) were dried and purified according to the literature when necessary. Reaction progress and purity of the compounds were checked by thin-layer chromatography (TLC) on pre-coated silica gel F254 plates from Merck and compounds were visualized either by exposure to UV light or by dipping in $1 \%$ aqueous potassium permanganate solution. Silica gel chromatographic columns (60-120 mesh) were used for the separations. By using Perkin-Elmer 141 polarimeter<smiles>C#CCO[C@H]1C([C@H]2COC(C)(C)O2)O[C@@H]2OC(C)(C)O[C@H]12</smiles><smiles>CC(=O)c1ccccc1OCCCCn1nncc1CO[C@H]1[C@H](C(O)CO)O[C@@H]2OC(C)(C)O[C@H]12</smiles><smiles>CC(=O)c1ccccc1OCCCCn1nncc1CO[C@H]1C(C2COC(C)(C)O2)O[C@@H]2OC(C)(C)O[C@H]12</smiles><smiles>CC(=O)c1ccccc1OCCCCn1nncc1CO[C@H]1C(C=O)O[C@@H]2OC(C)(C)O[C@H]12</smiles><smiles>CC1(C)CO[C@@H]2[C@H](OC3/C=C/C(=O)c4ccccc4OCCCCn4nncc4CO[C@H]32)O1</smiles><smiles>CC1(C)O[C@H]2O[C@H]3c4cc(n(-c5ccccc5)n4)-c4ccccc4OCCCCCn4nncc4CO[C@@H]3[C@H]2O1</smiles>

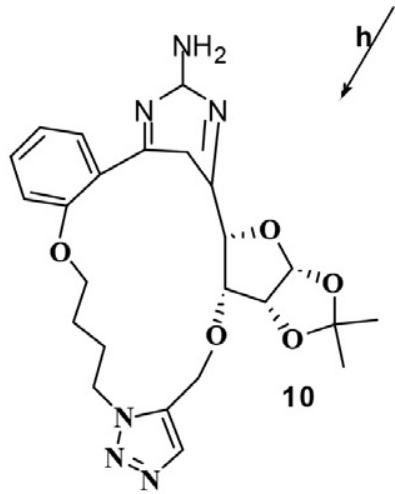

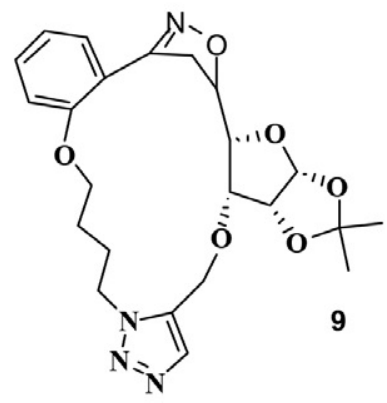

Sheme 1

Reagents and conditions: (a) 1,4-dibromobutane, $\mathrm{K} 2 \mathrm{CO} 3$, DMF; (b) NaN3; (c) sodium ascorbate, $\mathrm{CuSO} 4 \cdot 5 \mathrm{H} 2 \mathrm{O}, \mathrm{H} 2 \mathrm{O}, \mathrm{CH} 2 \mathrm{Cl} 2$; (d) 60\% ACOH; (e) $\mathrm{NaIO} 4, \mathrm{CH} 2 \mathrm{Cl}$; (f) $\mathrm{KOH}$; (g) NH2OH$\cdot \mathrm{HCl}, \mathrm{NaOAc}, \mathrm{AcOH}$; (h) guanidine hydrochloride; (i) $\mathrm{PhNHNH} 2, \mathrm{NaOAc}, \mathrm{AcOH}$. 


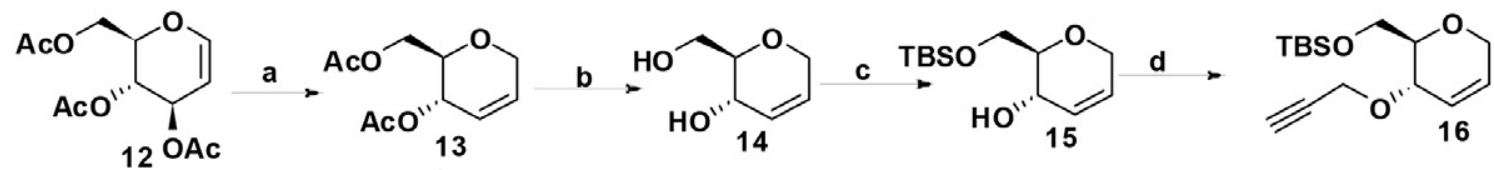

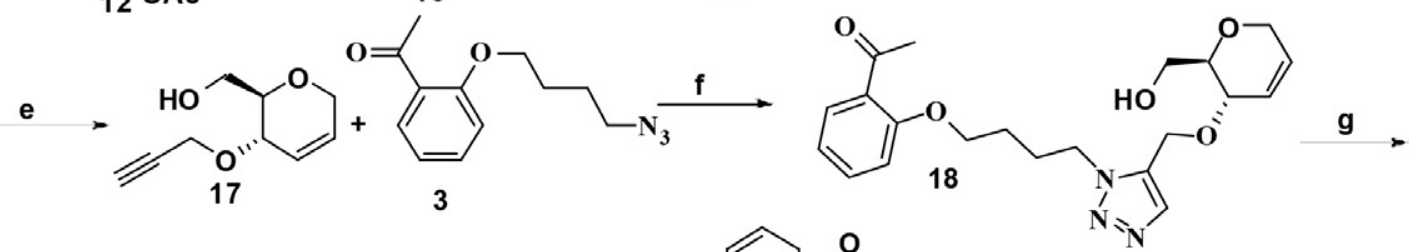<smiles>CC(=O)c1ccccc1OCCCCn1nncc1CO[C@H]1C=CCO[C@@H]1C=O</smiles><smiles>O=C1/C=C/C2OCC=CC2OCc2ccnn2CCCOc2ccccc21</smiles><smiles>C1=C[C@H]2OCC3C=C[C@H]3OCc3cnnn3CCCOc3ccccc3C3=NN(c4ccccc4)C(C3)C2OC1</smiles>
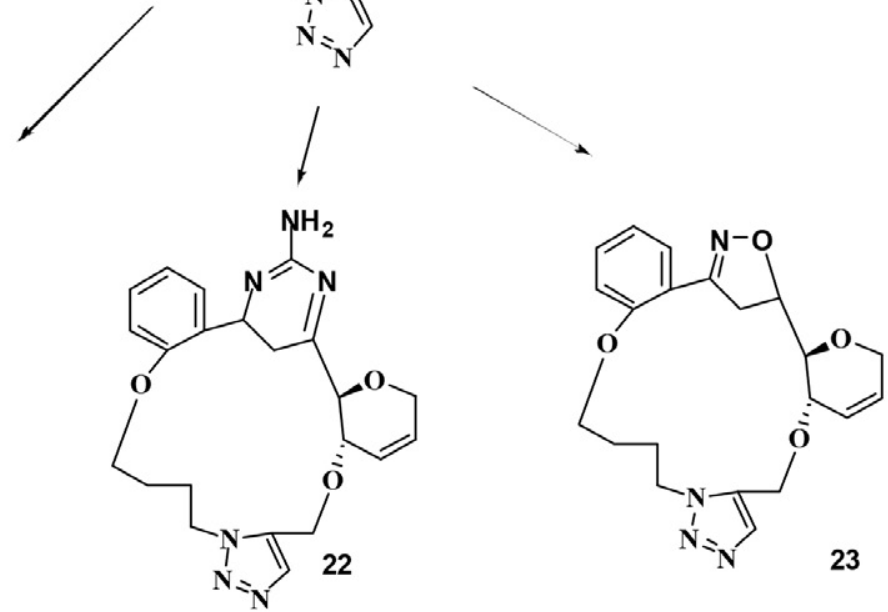

Sheme 2

Reagents and conditions: (a) $\mathrm{Et}_{3} \mathrm{Si}_{1} \mathrm{BF}_{3}$, DMF; (b) NaOMe; (c) TBDMSCl, $\mathrm{Et}_{3} \mathrm{~N}$, imidazole; (d) propargyl bromide, $n$ - $\mathrm{Bu}_{4} \mathrm{NHSO}_{4}$; (e) TBAF, THF; (f) sodium ascorbate, $\mathrm{CuSO}_{4} \cdot 5 \mathrm{H}_{2} \mathrm{O}, \mathrm{H}_{2} \mathrm{O}, \mathrm{CH}_{2} \mathrm{Cl}_{2}$; (g) IBX, $\mathrm{CH}_{2} \mathrm{Cl}_{2}$; (h) $\mathrm{KOH}$; (i) $\mathrm{PhNHNH}_{2}, \mathrm{NaOAc}$, AcOH; (j) guanidine hydrochloride; (k) $\mathrm{NH}_{2} \mathrm{OH} \cdot \mathrm{HCl}, \mathrm{NaOAc}, \mathrm{AcOH}$.

optical rotations were measured on a $2 \mathrm{~mL}$ cell with a path length of $1 \mathrm{dm}$ with $\mathrm{CHCl}_{3}$ or $\mathrm{CDCl}_{3}$ as the solvent. By using Fisher-Johns apparatus all melting points were measured and are uncorrected. IR spectra were recorded as $\mathrm{KBr}$ disks on a Perkin-Elmer FT IR spectrometer. The ${ }^{1} \mathrm{H}$ NMR and ${ }^{13} \mathrm{C}$ NMR spectra were recorded on a Varian Gemini spectrometer $\left(300 \mathrm{MHz}\right.$ for ${ }^{1} \mathrm{H}$ and $75 \mathrm{MHz}$ for ${ }^{13} \mathrm{C}$ ). Chemical shifts are reported as $\delta \mathrm{ppm}$ against TMS as the internal reference and coupling constants $(J)$ are reported in $\mathrm{Hz}$ units. Mass spectra were recorded on a VG micro mass $7070 \mathrm{H}$ spectrometer. Elemental analysis $(\mathrm{C}$, $\mathrm{H}, \mathrm{N}$ ) were determined by a Perkin-Elmer $240 \mathrm{CHN}$ elemental analyzer and were within $\pm 0.4 \%$ of theoretical values.

\section{1-(2-(4-Bromobutoxy)phenyl)ethanone (2)}

2-Hydroxyacetophenone $(1.2 \mathrm{~g}, 8.8 \mathrm{mmol})$, a catalytic amount of potassium carbonate and 1,4-dibromobutane $(1.9 \mathrm{~g}, 8.8 \mathrm{mmol})$ were stirred in DMF at $0{ }^{\circ} \mathrm{C}$ to room temperature for $8 \mathrm{~h}$, the reaction mixture was quenched with $\mathrm{NH}_{4} \mathrm{Cl}$, thereafter the reaction mixture was concentrated under reduced pressure, the product was extracted with ethyl acetate, washed with brine and dried over sodium sulphate and purified by column chromatography (60-120 mesh, $12 \%$ ethyl acetate in hexane) to give compound 2 ( $2 \mathrm{~g}, 7.3 \mathrm{mmol}, 84 \%)$. Mp $189^{\circ} \mathrm{C} .{ }^{1} \mathrm{H}$ NMR $\left(300 \mathrm{MHz}, \mathrm{CDCl}_{3}\right): \delta 7.37-7.42(\mathrm{~m}, 2 \mathrm{H}, \mathrm{Ar}-\mathrm{H}), 7.10-7.12$ (m, 2H, Ar-H), $4.09\left(\mathrm{~m}, 2 \mathrm{H}, \mathrm{CH}_{2}\right), 3.50\left(\mathrm{~m}, 2 \mathrm{H}, \mathrm{CH}_{2}\right)$, $2.56\left(\mathrm{~s}, 3 \mathrm{H}, \mathrm{CH}_{3}\right), 1.90-1.62\left(\mathrm{~m}, 4 \mathrm{H}, \mathrm{CH}_{2}\right) ;{ }^{13} \mathrm{C} \mathrm{NMR}(75$ $\left.\mathrm{MHz}, \mathrm{CDCl}_{3}\right): \delta$ 196.0, 162.1, 134.0, 122.5, 120.2, 117.9, 68.4, 30.5, 29.5, 29.1; MS: $m / z\left(\mathrm{M}^{+}+\mathrm{H}\right) 271$. Anal. Calcd for $\mathrm{C}_{12} \mathrm{H}_{15} \mathrm{BrO}_{2}$ : C, 53.15; $\mathrm{H}, 5.58$; Found: $\mathrm{C}, 52.98 ; \mathrm{H}$, 5.45 .

1-(2-(4-(5-)((3a $R, 5 R, 6 R, 6 \mathrm{a} R)-5-((S)-2,2-D i m e t h y l-1,3-$ dioxolan-4-yl)-2,2-dimethyltetrahydrofuro[2,3-d][1,3] dioxol-6-yloxy)methyl)-1 $H$-1,2,3-triazol-1-yl)butoxy) phenyl)ethanone (5)

The compound $2(1.90 \mathrm{~g}, 6.9 \mathrm{mmol})$ and sodium azide $(0.500 \mathrm{~g}, 7.6 \mathrm{mmol})$ was stirred in methanol at reflux 
temperature for $6 \mathrm{~h}$, the reaction mixture was concentrated under reduced pressure, the product extracted with ethyl acetate and evaporated to give $3(1.50 \mathrm{~g})$ in quantitative yield as a yellow coloured liquid, which was used for the next reaction.

To the solution containing alkyne $4(1.45 \mathrm{~g}, 4.8$ $\mathrm{mmol}$ ), azide $3(1.50 \mathrm{~g}, 6.4 \mathrm{mmol})$ in dichloromethane (10 $\mathrm{mL})$ and water $(10 \mathrm{~mL})$ were added $\mathrm{CuSO}_{4} \cdot 5 \mathrm{H}_{2} \mathrm{O}(0.110$ $\mathrm{g})$ and sodium ascorbate $(0.114 \mathrm{~g})$; the resulting suspension was stirred at room temperature for about $6 \mathrm{~h}$, the mixture was diluted with $5 \mathrm{~mL}$ dichloromethane and $5 \mathrm{~mL}$ water. The organic phase was separated, washed with brine, dried over sodium sulphate and concentrated under reduced pressure; the crude product thus obtained was purified by column chromatography on silica gel $(60-120$ mesh, hexane/EtOAc 65:35) to afford 5 (3.290 g, 6.1 mmol, $76 \%$ ) as a white powder. Mp $249{ }^{\circ} \mathrm{C}$. ${ }^{1} \mathrm{H}$ NMR (300 $\left.\mathrm{MHz}, \mathrm{CDCl}_{3}\right): \delta 8.04(\mathrm{~s}, 1 \mathrm{H}, \mathrm{Ar}-\mathrm{H}), 7.32-7.10(\mathrm{~m}, 4 \mathrm{H}$, $\operatorname{ArH}), 5.56\left(\mathrm{~d}, J=3.7 \mathrm{~Hz}, 1 \mathrm{H}, \mathrm{C}_{1} \mathrm{H}\right), 4.63\left(\mathrm{~m}, 1 \mathrm{H}, \mathrm{C}_{2} \mathrm{H}\right)$, $4.59\left(\mathrm{~s}, 2 \mathrm{H}, \mathrm{CH}_{2}\right), 4.41\left(\mathrm{dd}, J_{1}=3.1 \mathrm{~Hz}, J_{2}=7.3 \mathrm{~Hz}, 1 \mathrm{H}\right.$, $\left.\mathrm{C}_{5} \mathrm{H}\right), 4.19-4.13\left(\mathrm{~m}, 4 \mathrm{H}, \mathrm{CH}_{2}\right), 4.09-3.96\left(\mathrm{~m}, 3 \mathrm{H}, \mathrm{C}_{4} \mathrm{H}\right.$, $\left.2 \times \mathrm{C}_{6} \mathrm{H}\right), 3.75\left(\mathrm{dd}, J_{1}=8.8 \mathrm{~Hz}, J_{2}=4.1 \mathrm{~Hz}, 1 \mathrm{H}, \mathrm{C}_{3} \mathrm{H}\right), 2.52$ (s, $\left.3 \mathrm{H}, \mathrm{CH}_{3}\right), 1.78-1.75\left(\mathrm{~m}, 4 \mathrm{H}, 2 \times \mathrm{CH}_{2}\right), 1.51(\mathrm{~s}, 3 \mathrm{H}$, $\left.\mathrm{CH}_{3}\right), 1.40\left(\mathrm{~s}, 3 \mathrm{H}, \mathrm{CH}_{3}\right), 1.36\left(\mathrm{~s}, 6 \mathrm{H}, 2 \times \mathrm{CH}_{3}\right) ;{ }^{13} \mathrm{C} \mathrm{NMR}$ $\left(75 \mathrm{MHz}, \mathrm{CDCl}_{3}\right): \delta 196.0,162.0,142.4,135.8,129.4$, 120.4, 117.9, 110.2, 106.2, 82.6, 79.4, 73.9, 68.6, 67.8, 65.1, 41.6, 27.5, 26.4, 25.4; MS: $m / z\left(\mathrm{M}^{+}+\mathrm{H}\right)$ 532. Anal. Calcd for $\mathrm{C}_{27} \mathrm{H}_{37} \mathrm{~N}_{3} \mathrm{O}_{8}$ : C, 61.00; H, 7.02; N, 7.90; Found: C, 60.69; H, 6.95; N, 7.66.

1-(2-(4-(5-)((3aR,5R,6R,6aR)-5-((S)-1,2-Dihydroxyethyl)-2,2-dimethyltetrahydrofuro[2,3-d][1,3] dioxol-6yloxy)methyl)-1H-1,2,3-triazol-1-yl)butoxy)phenyl) ethanone (6)

A mixture of 5 ( $3 \mathrm{~g}, 5.6 \mathrm{mmol})$ in $60 \%$ aq. $\mathrm{AcOH}(25$ $\mathrm{mL}$ ) was stirred at room temperature for $12 \mathrm{~h}$. Reaction mixture was neutralized with anhydrous $\mathrm{NaHCO}_{3}(15 \mathrm{~g})$ and extracted with EtOAc $(3 \times 40 \mathrm{~mL})$. The combined organic layers were dried $\left(\mathrm{Na}_{2} \mathrm{SO}_{4}\right)$, evaporated and the residue was purified by column chromatography (60-120 mesh silica gel, $40 \%$ ethyl acetate in petroleum ether) to afford $6(2.6 \mathrm{~g}, 5.2 \mathrm{mmol}, 92 \%)$ as a pale yellow solid. Mp $256^{\circ} \mathrm{C} .{ }^{1} \mathrm{H}$ NMR $\left(300 \mathrm{MHz}, \mathrm{CDCl}_{3}\right): \delta 8.09(\mathrm{~s}, 1 \mathrm{H}, \mathrm{Ar}-\mathrm{H})$, 7.36-7.20 (m, 4H, ArH), $5.46\left(\mathrm{~d}, J=3.7 \mathrm{~Hz}, 1 \mathrm{H}, \mathrm{C}_{1} \mathrm{H}\right)$, $4.43\left(\mathrm{~m}, 1 \mathrm{H}, \mathrm{C}_{2} \mathrm{H}\right), 4.39\left(\mathrm{~s}, 2 \mathrm{H}, \mathrm{CH}_{2}\right), 4.31(\mathrm{~d}, J=3.1 \mathrm{~Hz}$, $\left.1 \mathrm{H}, \mathrm{C}_{5} \mathrm{H}\right), 4.18-4.12\left(\mathrm{~m}, 4 \mathrm{H}, \mathrm{CH}_{2}\right), 4.06-3.99(\mathrm{~m}, 3 \mathrm{H}$, $\left.\mathrm{C}_{4} \mathrm{H}, 2 \times \mathrm{C}_{6} \mathrm{H}\right), 3.65\left(\mathrm{dd}, J_{1}=8.8 \mathrm{~Hz}, J_{2}=4.1 \mathrm{~Hz}, 1 \mathrm{H}\right.$, $\mathrm{C}_{3} \mathrm{H}$ ), 2.44 (brs, $\left.1 \mathrm{H}, \mathrm{OH}\right), 1.78-1.75\left(\mathrm{~m}, 4 \mathrm{H}, 2 \times \mathrm{CH}_{2}\right.$ ), 1.52 (brs, $1 \mathrm{H}, \mathrm{OH}), 1.41$ (s, $\left.3 \mathrm{H}, \mathrm{CH}_{3}\right), 1.30\left(\mathrm{~s}, 3 \mathrm{H}, \mathrm{CH}_{3}\right)$, $1.26\left(\mathrm{~s}, 3 \mathrm{H}, \mathrm{CH}_{3}\right) ;{ }^{13} \mathrm{C} \mathrm{NMR}\left(75 \mathrm{MHz}, \mathrm{CDCl}_{3}\right): \delta 196.5$, 161.5, 142.4, 133.6, 127.9, 120.2, 117.9, 108.2, 98.6, 81.9, 79.6, 70.6, 47.4, 26.4, 25.1, 20.9; MS: $m / z\left(\mathrm{M}^{+}+\mathrm{Na}\right) 514$. Anal. Calcd for $\mathrm{C}_{24} \mathrm{H}_{33} \mathrm{~N}_{3} \mathrm{O}_{8}: \mathrm{C}, 58.64 ; \mathrm{H}, 6.77 ; \mathrm{N}, 8.55$; Found: C, 58.39; H, 6.55; N, 8.36.

$(5 \mathrm{a} S, 9 \mathrm{a} R, Z)-8,9 \mathrm{a}, 18,19,20,21-H e x a h y d r o-4 H$-benzo $[j]$ pyrano[2,3-o][1,2,3]triazolo $[5,1-c][1,9,4]$ dioxaazacyclohexadecin-12(5a $\mathrm{H})$-one (8)

To the solution of diol 6 ( $2.4 \mathrm{~g}, 4.88 \mathrm{mmol})$ in $\mathrm{CH}_{2}$ $\mathrm{Cl}_{2}(5 \mathrm{~mL}), \mathrm{NaIO}_{4}(0.530 \mathrm{~g}, 2.48 \mathrm{mmol})$ was added at $0{ }^{\circ} \mathrm{C}$ and stirred at room temperature for about $6 \mathrm{~h}$. The reaction mixture was filtered and washed with $\mathrm{CH}_{2} \mathrm{Cl}_{2}(2 \times 10 \mathrm{~mL})$, dried over $\mathrm{Na}_{2} \mathrm{SO}_{4}$ and evaporated to give keto aldehyde 7 $(2 \mathrm{~g})$ in quantitative yield as a yellow liquid, which was used for the next reaction.

The reaction mixture of keto aldehyde and $\mathrm{KOH}$ in methanol was stirred at reflux temperature for about $6 \mathrm{~h}$, the methanol was then removed from the reaction mixture, the product was extracted with ethyl acetate and washed with brine, dried over sodium sulphate, evaporated and the residue was purified by column chromatography $(60-120$ mesh silica gel, $40 \%$ ethyl acetate in petroleum ether) to afford $8(1.6 \mathrm{~g}, 3.62 \mathrm{mmol}, 92 \%)$ as a pale yellow solid. Mp $226{ }^{\circ} \mathrm{C} .{ }^{1} \mathrm{H}$ NMR $\left(300 \mathrm{MHz}, \mathrm{CDCl}_{3}\right): \delta 8.12(\mathrm{~s}, 1 \mathrm{H}$, Ar-H), 8.10-7.56 (m, 4H, Ar-H), $7.12(\mathrm{~d}, J=6.2 \mathrm{~Hz}, 1 \mathrm{H}$, $=\mathrm{CH}), 6.52(\mathrm{~d}, J=6.6 \mathrm{~Hz}, 1 \mathrm{H},=\mathrm{CH}), 5.58(\mathrm{~d}, J=3.7 \mathrm{~Hz}$, $\left.1 \mathrm{H}, \mathrm{C}_{1} \mathrm{H}\right), 4.04-3.98\left(\mathrm{~m}, 1 \mathrm{H}, \mathrm{C}_{4} \mathrm{H}\right), 4.63\left(\mathrm{~m}, 1 \mathrm{H}, \mathrm{C}_{2} \mathrm{H}\right)$, $4.60\left(\mathrm{~s}, 2 \mathrm{H}, \mathrm{CH}_{2}\right), 4.41\left(\mathrm{~d}, J=3.1 \mathrm{~Hz}, 1 \mathrm{H}, \mathrm{C}_{5} \mathrm{H}\right), 3.96$ $3.92\left(\mathrm{~m}, 4 \mathrm{H}, \mathrm{CH}_{2}\right), 3.62\left(\mathrm{dd}, J_{1}=8.8 \mathrm{~Hz}, J_{2}=4.1 \mathrm{~Hz}, 1 \mathrm{H}\right.$, $\left.\mathrm{C}_{3} \mathrm{H}\right), 1.75-1.72\left(\mathrm{~m}, 4 \mathrm{H}, 2 \times \mathrm{CH}_{2}\right), 1.24\left(\mathrm{~s}, 6 \mathrm{H}, 2 \times \mathrm{CH}_{3}\right)$; ${ }^{13} \mathrm{C}$ NMR $\left(75 \mathrm{MHz}, \mathrm{CDCl}_{3}\right): \delta 187.5,158.2,146.0,142.5$, $136.7,131.5,128.9,125.6,120.9,119.6,114.6,119.6$, 103.4, 83.6, 73.0, 70.6, 66.9, 50.9, 26.4, 24.0; MS: $\mathrm{m} / \mathrm{z}$ $\left(\mathrm{M}^{+}+\mathrm{H}\right)$ 442. Anal. Calcd for $\mathrm{C}_{23} \mathrm{H}_{27} \mathrm{~N}_{3} \mathrm{O}_{6}: \mathrm{C}, 62.57 ; \mathrm{H}$, 6.16; N, 9.52; Found: C, 62.39; H, 5.95; N, 9.26.

$\left(3^{3 \mathrm{a}} R, 3^{5} S, 3^{6} R, 3^{6 \mathrm{a}} R\right)-3^{2}, 3^{2}$-Dimethyl-2 $2^{4}, 2^{5}, 3^{3 \mathrm{a}}, 3^{5}, 3^{6}, 3^{6 \mathrm{a}}$ hexahdro- ${ }^{1} H-4,11$-dioxa-2 $(3,5)$-isoxazola- $6(5,1)$-triazola-3(5,6)-furo[2,3- $d][1,3]$-dioxola-1(1,2)benzenacycloundecaphane (9)

A mixture of compound $8(0.050 \mathrm{~g}, 0.113 \mathrm{mmol})$, hydroxylamine hydrochloride $(0.020 \mathrm{~g}, 0.28 \mathrm{mmol})$ and sodium acetate $(0.010 \mathrm{~g}, 0.12 \mathrm{mmol})$ in anhydrous glacial acetic acid $(20 \mathrm{~mL})$ was refluxed for $8 \mathrm{~h}$. The reaction mixture was concentrated in vacuo and then poured into ice cold water, the solid thus separated was filtered off, washed with water and crystallized from ethanol to afford pure $\mathbf{1 0}$ (0.035 g, $0.07 \mathrm{mmol}, 67 \%)$ as a brown solid. Mp $276^{\circ} \mathrm{C}$. ${ }^{1} \mathrm{H}$ NMR $\left(300 \mathrm{MHz}, \mathrm{CDCl}_{3}\right): \delta 8.04(\mathrm{~s}, 1 \mathrm{H}, \mathrm{Ar}-\mathrm{H}), 7.62$ $7.49(\mathrm{~m}, 4 \mathrm{H}, \mathrm{Ar}-\mathrm{H}), 5.42\left(\mathrm{~d}, J=3.7 \mathrm{~Hz}, 1 \mathrm{H}, \mathrm{C}_{1} \mathrm{H}\right), 4.69(\mathrm{~s}$, $\left.2 \mathrm{H}, \mathrm{CH}_{2}\right), 4.60\left(\mathrm{~m}, 1 \mathrm{H}, \mathrm{C}_{2} \mathrm{H}\right), 4.41\left(\mathrm{dd}, J_{1}=3.1 \mathrm{~Hz}, J_{2}=\right.$ $\left.7.3 \mathrm{~Hz}, 1 \mathrm{H}, \mathrm{C}_{4} \mathrm{H}\right), 3.93-3.88\left(\mathrm{~m}, 4 \mathrm{H}, \mathrm{CH}_{2}\right), 3.60\left(\mathrm{dd}, J_{1}=\right.$ $\left.8.9 \mathrm{~Hz}, J_{2}=4.1 \mathrm{~Hz}, 1 \mathrm{H}, \mathrm{C}_{3} \mathrm{H}\right), 3.59-3.55(\mathrm{~m}, 1 \mathrm{H}, \mathrm{CH})$, $3.04\left(\mathrm{~m}, 2 \mathrm{H}, \mathrm{CH}_{2}\right), 1.93-1.78\left(\mathrm{~m}, 4 \mathrm{H}, 2 \times \mathrm{CH}_{2}\right), 1.26(\mathrm{~s}, 6 \mathrm{H}$, $\left.2 \times \mathrm{CH}_{3}\right) ;{ }^{13} \mathrm{C}$ NMR $\left(75 \mathrm{MHz}, \mathrm{CDCl}_{3}\right): \delta 156.4,142.5$, 131.9, 128.9, 121.4, 117.8, 114.6, 111.6, 107.1, 83.6, 82.6, 81.6, 72.9, 66.5, 63.2, 50.6, 36.9, 26.9, 23.9. MS: $\mathrm{m} / \mathrm{z}$ $\left(\mathrm{M}^{+}+\mathrm{H}\right)$ 457. Anal. Calcd for $\mathrm{C}_{23} \mathrm{H}_{28} \mathrm{~N}_{4} \mathrm{O}_{6}: \mathrm{C}, 60.52 ; \mathrm{H}$, 6.18; N, 12.27; Found: C, 59.99; H, 5.97; N, 12.01.

$\left(2^{4} R, 3^{\mathrm{a}} R, 3^{5} R, 3^{6} R, 3^{6 \mathrm{a}} R\right)-3^{2}, 3^{2}$-D imethyl- $2^{4}, 2^{5}$, $3^{3 a}, 3^{5}, 3^{6}, 3^{6 a}$-heahydro-6 ${ }^{1} H-4,11$-dioxa-2 $(4,6)$-pyrimi-

Srinivas and Rao: Synthesis and Anticancer Activity ... 
dana-6(5,1)-triazola-3(5,6)-furo $[2,3-d][1,3]$-dioxola-1(1,2)-benzenecycloundecaphane- $2^{3}$-amine (10)

To the solution of $8(0.050 \mathrm{~g}, 0.113 \mathrm{mmol})$ and guanidine hydrochloride $(0.029 \mathrm{~g}, 0.3 \mathrm{mmol})$ in ethanol $(20 \mathrm{~mL})$ was added aq. $\mathrm{NaOH}$ solution $(5 \mathrm{~mL})$. The reaction mixture was refluxed for about $6 \mathrm{~h}$. Then it was poured in cold $10 \% \mathrm{HCl}(50 \mathrm{~mL})$ solution and the precipitate obtained was collected by filtration, washed with water until free from acid and recrystallized from toluene-ethanol (3:2) to give pure $\mathbf{1 0}$ as a brown solid $(0.019$ g, $0.04 \mathrm{mmol}, 63 \%)$. Mp $266{ }^{\circ} \mathrm{C} .{ }^{1} \mathrm{H}$ NMR $(300 \mathrm{MHz}$, $\left.\mathrm{CDCl}_{3}\right): \delta 8.02(\mathrm{~s}, 1 \mathrm{H}, \mathrm{Ar}-\mathrm{H}), 7.12\left(\mathrm{~s}, 2 \mathrm{H}, \mathrm{NH}_{2}\right), 6.94$ $7.10(\mathrm{~m}, 4 \mathrm{H}, \mathrm{Ar}-\mathrm{H}), 5.49\left(\mathrm{~d}, J=3.7 \mathrm{~Hz}, 1 \mathrm{H}, \mathrm{C}_{1} \mathrm{H}\right), 4.66(\mathrm{~s}$, $\left.2 \mathrm{H}, \mathrm{CH}_{2}\right), 4.53\left(\mathrm{~m}, 1 \mathrm{H}, \mathrm{C}_{2} \mathrm{H}\right), 4.41\left(\mathrm{~m}, 1 \mathrm{H}, \mathrm{C}_{4} \mathrm{H}\right), 3.90-$ $3.83\left(\mathrm{~m}, 4 \mathrm{H}, 2 \times \mathrm{CH}_{2}\right), 3.62\left(\mathrm{dd}, J_{1}=3.1 \mathrm{~Hz}, J_{2}=7.3 \mathrm{~Hz}\right.$, $\left.1 \mathrm{H}, \mathrm{C}_{3} \mathrm{H}\right), 3.04\left(\mathrm{~m}, 2 \mathrm{H}, \mathrm{CH}_{2}\right), 2.54(\mathrm{~m}, 1 \mathrm{H}, \mathrm{CH}), 1.78$ $1.90\left(\mathrm{~m}, 4 \mathrm{H}, 2 \times \mathrm{CH}_{2}\right), 1.20\left(\mathrm{~s}, 6 \mathrm{H}, 2 \times \mathrm{CH}_{3}\right) ;{ }^{13} \mathrm{C}$ NMR $(75$ $\left.\mathrm{MHz}, \mathrm{CDCl}_{3}\right): \delta 164.5,163.2,154.5,142.6,128.9,126.8$, $120.4,112.4,105.9,83.0,77.6,72.4,65.8,50.6,43.6$, 32.0, 27.0, 24.0; MS: $\mathrm{m} / z\left(\mathrm{M}^{+}+\mathrm{Na}\right)$ 505. Anal. Calcd for $\mathrm{C}_{24} \mathrm{H}_{30} \mathrm{~N}_{6} \mathrm{O}_{5}: \mathrm{C}, 59.74 ; \mathrm{H}, 6.27$; N, 17.42; Found: C, $59.59 ; \mathrm{H}, 6.07 ; \mathrm{N}, 17.01$.

$\left(3^{3 \mathrm{a}} R, 3^{5} R, 3^{6} R\right)-3^{2}, 3^{2}$-Dimethyl-2 ${ }^{1}$-phenyl-2 ${ }^{4}, 2^{5}$, $3^{3 a}, 3^{5}, 3^{6}, 3^{6 a}$-hexahydro-2 ${ }^{1} H, 6^{1 H}-4,11$-dioxa-6(5,1)-triazola-2(3,5)-pyrazola-3(5,6)-furo-[2,3- $d][1,3]$-dioxola-1(1,2))-benzenecycloundecaphane (11)

The mixture of compound $8(0.050 \mathrm{~g}, 0.113 \mathrm{mmol})$, phenylhydrazine $(0.025 \mathrm{~g}, 0.23 \mathrm{mmol})$ and anhydrous sodium acetate $(0.012 \mathrm{~g}, 0.14 \mathrm{mmol})$ in glacial acetic acid $(20 \mathrm{~mL})$ was refluxed for about $7 \mathrm{~h}$. The reaction mixture was concentrated in vacuo and cooled at room temperature, the solid thus separated was filtered off, then washed thoroughly with water, the unmilled product thus obtained was purified by column chromatography on silica gel with hexane-ethyl acetate as eluent to afford pure compound $11(0.044 \mathrm{~g}, 0.08 \mathrm{mmol}, 73 \%) . \mathrm{Mp} 276^{\circ} \mathrm{C} .{ }^{1} \mathrm{H}$ NMR $(300$ $\mathrm{MHz}, \mathrm{CDCl}_{3}$ ): $\delta 8.09(\mathrm{~s}, 1 \mathrm{H}, \mathrm{ArH}), 7.25-7.10(\mathrm{~m}, 5 \mathrm{H}$, ArH), 6.95-7.14 (m, 4H, ArH), $5.40(\mathrm{~d}, J=3.7 \mathrm{~Hz}, 1 \mathrm{H}$, $\left.\mathrm{C}_{1} \mathrm{H}\right), 5.25(\mathrm{~d}, J=1.8 \mathrm{~Hz}, 1 \mathrm{H}, \mathrm{CHN}), 4.54\left(\mathrm{~s}, 2 \mathrm{H}, \mathrm{CH}_{2}\right)$, $4.50\left(\mathrm{~m}, 1 \mathrm{H}, \mathrm{C}_{2} \mathrm{H}\right), 4.38\left(\mathrm{~m}, 1 \mathrm{H}, \mathrm{C}_{4} \mathrm{H}\right), 3.90-3.85(\mathrm{~m}, 4 \mathrm{H}$, $\left.\mathrm{CH}_{2}\right), 3.59\left(\mathrm{dd}, J_{1}=3.1 \mathrm{~Hz}, J_{2}=7.3 \mathrm{~Hz}, 1 \mathrm{H}, \mathrm{C}_{3} \mathrm{H}\right), 3.01$ $\left(\mathrm{m}, 2 \mathrm{H}, \mathrm{CH}_{2}\right), 1.89-1.78\left(\mathrm{~m}, 4 \mathrm{H}, 2 \times \mathrm{CH}_{2}\right), 1.24(\mathrm{~s}, 6 \mathrm{H}$, $\left.2 \times \mathrm{CH}_{3}\right) ;{ }^{13} \mathrm{C}$ NMR $\left(75 \mathrm{MHz}, \mathrm{CDCl}_{3}\right): \delta 157.1,151.5$, $142.4,131.5,129.5,128.6,120.4,116.9,114.5,112.0$, 105.9, 85.0, 83.5, 82.3, 72.4, 66.5, 50.4, 48.1, 32.6, 27.1, 23.8; MS: $m / z\left(\mathrm{M}^{+}+\mathrm{H}\right)$ 532. Anal. Calcd for $\mathrm{C}_{29} \mathrm{H}_{33} \mathrm{~N}_{5} \mathrm{O}_{5}$ : C, 65.52; H, 6.26; N,13.17; Found: C, 65.29; H, 5.97; N, 12.91 .

((2R,3S)-3-Acetoxy-3,6-dihydro-2H-pyran-2-yl)methyl Acetate (13)

Tri- $O$-acetyl-D-glucal (12) $(3.0 \mathrm{~g}, 11.0 \mathrm{mmol})$ was dissolved in anhydrous dichloromethane $(5 \mathrm{~mL})$, the solution was cooled to $0{ }^{\circ} \mathrm{C}$, triethylsilane $(1.53 \mathrm{~g}, 13.2 \mathrm{mmol})$ was added and the mixture was stirred for five minutes.
Boron trifluoride diethyl etherate $(690 \mu \mathrm{L}$ of a $40 \mathrm{w} \%$ solution in diethyl ether, $11.02 \mathrm{mmol}$ ) was added drop wise and the reaction mixture was stirred for $90 \mathrm{~min}$. The mixture was poured into a saturated solution of $\mathrm{NaHCO}_{3}$. The organic layer was washed with water, dried over Na${ }_{2} \mathrm{SO}_{4}$ and concentrated under reduced pressure. Column chromatography on silica gel (PE/EtOAc, 3:1) yielded the title compound $\mathbf{1 3}(2.24 \mathrm{~g}, 10 \mathrm{mmol}, 95 \%)$ as a colourless syrup. $[\alpha]_{20}{ }_{20}:+115.5\left(c=1.00, \mathrm{CHCl}_{3}\right) .{ }^{1} \mathrm{H}$ NMR $(300$ $\left.\mathrm{MHz}, \mathrm{CDCl}_{3}\right): \delta 5.87-5.84(\mathrm{~m}, 2 \mathrm{H},=\mathrm{CH}), 4.95(\mathrm{~m}, 1 \mathrm{H}$, $\mathrm{OCH}), 4.03-3.99(\mathrm{~m}, 1 \mathrm{H}, \mathrm{CH}), 4.12-4.09\left(\mathrm{~m}, 4 \mathrm{H}, \mathrm{OCH}_{2}\right)$, $2.20\left(\mathrm{~s}, 6 \mathrm{H}, \mathrm{COCH}_{3}\right) ;{ }^{13} \mathrm{C}$ NMR $\left(75 \mathrm{MHz}, \mathrm{CDCl}_{3}\right): \delta$ 170.2, 127.2, 125.8, 73.6, 65.1, 64.0, 62.5, 21.1; MS: $\mathrm{m} / \mathrm{z}$ $\left(\mathrm{M}^{+}+\mathrm{H}\right)$ 215. Anal. Calcd for $\mathrm{C}_{10} \mathrm{H}_{14} \mathrm{O}_{5}$ : $\mathrm{C}, 56.07 ; \mathrm{H}, 6.59$; Found: C, 55.82; H, 6.35.

\section{(2R,3S)-2-((tert-Butyldimethylsilyloxy)methyl)-3,6-di- hydro-2H-pyran-3-ol (15)}

At room temperature diacetate $\mathbf{1 3}(2.10 \mathrm{~g}, 9.8 \mathrm{mmol})$ was treated with a catalytic amount of sodium methoxide in methanol $(100 \mathrm{~mL})$. The free hydroxyl unsaturated glycoside was obtained after evaporation of the solvent in quantitative yield and used without further purification. This diol was treated with 2.50 equiv. of TBDMSCl (3.14 g, $20 \mathrm{mmol}), 2.6$ equiv. of $\mathrm{NEt}_{3}(3.2 \mathrm{~mL}, 23 \mathrm{mmol})$, and 0.05 equiv. of imidazole $(30 \mathrm{mg}, 0.44 \mathrm{mmol})$ in $\mathrm{CH}_{2} \mathrm{Cl}_{2}$ $(30 \mathrm{~mL})$ at room temperature for $24 \mathrm{~h}$ (until TLC analysis showed no more starting material). After addition of 25 $\mathrm{mL}$ of water and extraction with $3 \times 30 \mathrm{~mL}$ of $\mathrm{CH}_{2} \mathrm{Cl}_{2}$, the organic layer was dried under reduced pressure. After evaporation of the solvent the residue was purified by column chromatography using petroleum ether/ethyl acetate as the eluent yielding the title compound $\mathbf{1 5}(1.94 \mathrm{~g}, 7.6$ mmol, $85 \%)$ as a colourless syrup. ${ }^{1} \mathrm{H}$ NMR $(300 \mathrm{MHz}$, $\left.\mathrm{CDCl}_{3}\right): \delta 6.0-5.82(\mathrm{~m}, 2 \mathrm{H},=\mathrm{CH}), 5.42(\mathrm{~d}, J=6.5 \mathrm{~Hz}, 1 \mathrm{H}$, $\mathrm{CH}$,), 4.50 (brs, 1H, OH), 4.20-4.12 (m, 1H, CH), 3.91$3.80\left(\mathrm{~m}, 4 \mathrm{H}, \mathrm{CH}_{2}\right), 0.98(\mathrm{~s}, 9 \mathrm{H}, t-\mathrm{Bu}), 0.24\left(\mathrm{~s}, 6 \mathrm{H}, \mathrm{CH}_{3}\right)$; ${ }^{13} \mathrm{C}$ NMR $\left(75 \mathrm{MHz}, \mathrm{CDCl}_{3}\right): \delta 127.5,125.6,84.6,81.5$, 73.6, 62.7, 25.6, 18.1; MS: $\mathrm{m} / z\left(\mathrm{M}^{+}+\mathrm{Na}\right)$ 267. Anal. Calcd for $\mathrm{C}_{12} \mathrm{H}_{24} \mathrm{O}_{3} \mathrm{Si}$ : C, 58.97; H, 9.90; Found: C, 58.62; H, 9.75 .

tert-Butyldimethyl(((2R,3S)-3-(prop-2-ynyloxy)-3,6-dihydro-2H-pyran-2yl)methoxy)silane (16)

In toluene $(1.6 \mathrm{~mL})$ the solution of alcohol $14(0.400$ g, 1.63 mmol, 1.0 equiv.) was added, $35 \%$ aqueous solution of $\mathrm{NaOH}(1.6 \mathrm{~mL})$, propargyl bromide ( $80 \%$ solution in toluene, $363 \mu \mathrm{L}, 2.4 \mathrm{mmol}, 1.5$ equiv.), and $n-\mathrm{Bu}_{4} \mathrm{~N}$ $\mathrm{HSO}_{4}(280 \mathrm{mg}, 0.8 \mathrm{mmol}, 0.5$ equiv.) was added. After 6 $\mathrm{h}$ of vigorous stirring at room temperature, $\mathrm{Et}_{2} \mathrm{NH}$ (1.6 $\mathrm{mL}$ ) was added. The reaction mixture was stirred for $1 \mathrm{~h}$, poured into ice water, cautiously neutralized by addition of a $3 \mathrm{M}$ solution of hydrochloric acid, and extracted with EtOAc. The combined organic extracts were washed with brine, dried over $\mathrm{MgSO}_{4}$, filtered and concentrated under reduced pressure. The crude material was purified by flash 
chromatography on silica gel (hexane/EtOAc 85:15) to afford propargyl ether as a colorless oil $(0.345 \mathrm{~g}, 1.21 \mathrm{mmol}$, $75 \%) .{ }^{1} \mathrm{H}$ NMR $\left(300 \mathrm{MHz}, \mathrm{CDCl}_{3}\right): \delta 6.03-5.80(\mathrm{~m}, 2 \mathrm{H}$, $=\mathrm{CH}), 4.69(\mathrm{t}, J=3.9 \mathrm{~Hz}, 1 \mathrm{H}, \mathrm{CH}), 3.68\left(\mathrm{dd}, J_{l}=8.9 \mathrm{~Hz}\right.$, $\left.J_{2}=4.1 \mathrm{~Hz}, 1 \mathrm{H}, \mathrm{OCH}\right), 3.99-3.89\left(\mathrm{~m}, 6 \mathrm{H}, \mathrm{CH}_{2}\right), 3.20(\mathrm{~s}$, $1 \mathrm{H}, \mathrm{CH}), 0.96(\mathrm{~s}, 9 \mathrm{H}, t-\mathrm{Bu}), 0.23\left(\mathrm{~s}, 6 \mathrm{H}, \mathrm{CH}_{3}\right) ;{ }^{13} \mathrm{C} \mathrm{NMR}$ $\left(75 \mathrm{MHz}, \mathrm{CDCl}_{3}\right): \delta 127.2,124.9,78.0,76.2,74.2,64.2$, 63.2, 58.5, 25.3, 18.5; MS: $m / z\left(\mathrm{M}^{+}+\mathrm{H}\right)$ 283. Anal. Calcd for $\mathrm{C}_{15} \mathrm{H}_{26} \mathrm{O}_{3} \mathrm{Si}$ : C, 63.78; H, 9.28; Found: C, 63.62; $\mathrm{H}$, 8.95 .

((2R,3S)-3-(Prop-2-ynyloxy)-3,6-dihydro-2H-pyran-2yl)methanol (17)

In THF the stirred solution of $\mathbf{1 6}(0.325 \mathrm{~g}, 1.152$ mmol), catalytic amount of TBAF was added and stirred the reaction mixture at room temperature for about 15 $\mathrm{min}$, the product was extracted with ethyl acetate $(20 \mathrm{~mL})$. The combined organic extracts were washed with brine, dried over $\mathrm{MgSO}_{4}$, filtered, and concentrated in vacuo. The crude material was purified by flash chromatography on silica gel (60-120 mesh, hexane/EtOAc 70:30) to afford alcohol 17 as a yellow oil $(0.285 \mathrm{~g}, 1.69 \mathrm{~mol}, 85 \%)$. ${ }^{1} \mathrm{H}$ NMR (300 MHz, $\left.\mathrm{CDCl}_{3}\right): \delta 5.95-5.75(\mathrm{~m}, 2 \mathrm{H},=\mathrm{CH})$, $4.65(\mathrm{~d}, J=3.9 \mathrm{~Hz}, 1 \mathrm{H}, \mathrm{CH}), 4.52$ (brs, $1 \mathrm{H}, \mathrm{OH}), 4.09$ $4.11\left(\mathrm{~m}, 4 \mathrm{H}, \mathrm{OCH}_{2}\right), 3.64\left(\mathrm{dd}, J_{1}=4.1 \mathrm{~Hz}, J_{2}=8.9 \mathrm{~Hz}\right.$, $1 \mathrm{H}, \mathrm{OCH}), 3.76\left(\mathrm{~d}, J=6.8 \mathrm{~Hz}, 2 \mathrm{H}, \mathrm{OCH}_{2}\right), 3.28(\mathrm{~s}, 1 \mathrm{H}$, $\mathrm{CH}) ;{ }^{13} \mathrm{C}$ NMR $\left(75 \mathrm{MHz}, \mathrm{CDCl}_{3}\right): \delta 127.2,125.6,78.3$, 76.1, 74.1, 64.2, 61.4, 58.0; MS: $m / z\left(\mathrm{M}^{+}+\mathrm{H}\right)$ 169. Anal. Calcd for $\mathrm{C}_{9} \mathrm{H}_{12} \mathrm{O}_{3}: \mathrm{C}, 64.27 ; \mathrm{H}, 7.10$; Found: $\mathrm{C}, 64.02 ; \mathrm{H}$, 6.95 .

1-(2-(4-(5-(((2R,3S)-2-(Hydroxymethyl)-3,6-dihydro2H-pyran-3-yloxy)methyl)-1H-1,2,3-triazol-1-yl)butoxy)phenyl)ethanone (18)

To a solution containing alkyne $17(0.250 \mathrm{~g}, 1.48$ $\mathrm{mmol})$, azide $3(0.280 \mathrm{~g}, 1.20 \mathrm{mmol})$ in dichloromethane $(10 \mathrm{~mL})$ and water $(10 \mathrm{~mL})$ were added $\mathrm{CuSO}_{4} \cdot 5 \mathrm{H}_{2} \mathrm{O}$ $(0.110 \mathrm{~g})$ and sodium ascorbate $(0.114 \mathrm{~g})$. The resulting suspension was stirred at room temperature for $6 \mathrm{~h}$. After this time, the mixture was diluted with $5 \mathrm{~mL}$ dichloromethane and $5 \mathrm{~mL}$ water. The organic phase was separated, dried with sodium sulphate and concentrated at reduced pressure; the crude product thus obtained was purified by column chromatography on silica gel $(60-120$ mesh, hexane/EtOAc 60:40) to afford $\mathbf{1 8}(0.442 \mathrm{~g}, 1.10$ mol, $77 \%$ ) as a white powder. Mp $249-251^{\circ} \mathrm{C} .{ }^{1} \mathrm{H}$ NMR $\left(300 \mathrm{MHz}, \mathrm{CDCl}_{3}\right): \delta 8.10(\mathrm{~s}, 1 \mathrm{H}, \mathrm{Ar}-\mathrm{H}), 7.31-7.10(\mathrm{~m}$, $4 \mathrm{H}, \mathrm{ArH}), 5.80-5.76(\mathrm{~m}, 2 \mathrm{H},=\mathrm{CH}), 5.09$ (brs, $1 \mathrm{H}, \mathrm{OH})$, $4.68\left(\mathrm{~s}, 2 \mathrm{H}, \mathrm{CH}_{2}\right), 4.36-4.30\left(\mathrm{~m}, 6 \mathrm{H}, \mathrm{CH}_{2}\right), 3.86(\mathrm{~m}, 1 \mathrm{H}$, $\mathrm{CH}), 3.58\left(\mathrm{~m}, 2 \mathrm{H}, \mathrm{CH}_{2}\right), 3.28(\mathrm{q}, 1 \mathrm{H}, \mathrm{CH}), 2.46(\mathrm{~s}, 3 \mathrm{H}$, $\left.\mathrm{CH}_{3}\right), 1.76-1.75\left(\mathrm{~m}, 4 \mathrm{H}, \mathrm{CH}_{2}\right) ;{ }^{13} \mathrm{C}$ NMR $(75 \mathrm{MHz}$, $\left.\mathrm{CDCl}_{3}\right): \delta 195.0,165.2,142.8,134.8,128.7,127.8,125.8$, 120.2, 117.9, 78.6, 69.6, 64.8, 62.6, 47.9, 27.6, 26.8, 25.4; MS: $m / z\left(\mathrm{M}^{+}+\mathrm{H}\right)$ 402. Anal. Calcd for $\mathrm{C}_{21} \mathrm{H}_{27} \mathrm{~N}_{3} \mathrm{O}_{5}$ : C, 62.83; H, 6.78; N, 10.47; Found: C, 62.55; H, 6.57; N, 10.10 .
1-(2-(4-(5-(((2R,3S)-2-(Hydroxymethyl)-3,6-dihydro2H-pyran-3-yloxy)methyl)-1H-1,2,3-triazol-1-yl)butoxy)phenyl)ethanone (20)

In $\mathrm{CH}_{2} \mathrm{Cl}_{2}(5 \mathrm{~mL})$, IBX $(0.100 \mathrm{~g}, 0.35 \mathrm{mmol})$ to a solution of keto alcohol $18(0.400 \mathrm{~g}, 0.99 \mathrm{mmol})$ was added at $0{ }^{\circ} \mathrm{C}$ and stirred at room temperature for about $6 \mathrm{~h}$. The reaction mixture was filtered and washed with $\mathrm{CH}_{2} \mathrm{Cl}_{2}$ $(2 \times 10 \mathrm{~mL})$. It was dried $\left(\mathrm{Na}_{2} \mathrm{SO}_{4}\right)$ and evaporated to give keto aldehyde $19(0.325 \mathrm{~g})$ in quantitative yield as a yellow liquid, which was used as such for the next reaction.

The stirred reaction mixture of keto aldehyde 19 and $\mathrm{NaOH}(0.500 \mathrm{~g}, 12.5 \mathrm{mmol})$ in methanol $(5 \mathrm{~mL})$ was heated at reflux temperature for about $6 \mathrm{~h}$, thereafter methanol was removed from the reaction mixture, the product was extracted with ethyl acetate and washed with brine, dried over sodium sulphate, volatile components were evaporated and the residue purified by column chromatography (60-120 mesh silica gel, $40 \%$ ethyl acetate in petroleum ether) to afford $20(0.219 \mathrm{~g}, 0.57 \mathrm{mmol}, 70.58 \%)$ as a pale yellow solid. Mp 269-271 ${ }^{\circ} \mathrm{C} .{ }^{1} \mathrm{H}$ NMR $(300 \mathrm{MHz}$, $\left.\mathrm{CDCl}_{3}\right): \delta 8.09(\mathrm{~s}, 1 \mathrm{H}, \mathrm{ArH}), 7.36-7.18(\mathrm{~m}, 4 \mathrm{H}, \mathrm{ArH})$, $7.12(\mathrm{~d}, J=3.2 \mathrm{~Hz}, 1 \mathrm{H},=\mathrm{CH}), 6.59(\mathrm{~d}, J=3.9 \mathrm{~Hz}, 1 \mathrm{H}$, $=\mathrm{CH}), 5.87-5.84(\mathrm{~m}, 2 \mathrm{H},=\mathrm{CH}), 4.68\left(\mathrm{~s}, 2 \mathrm{H}, \mathrm{CH}_{2}\right), 3.99$ $3.95\left(\mathrm{~m}, 4 \mathrm{H}, \mathrm{CH}_{2}\right), 3.87(\mathrm{~m}, 2 \mathrm{H}, \mathrm{CH}), 3.70\left(\mathrm{~m}, 2 \mathrm{H}, \mathrm{CH}_{2}\right)$, $1.70-1.62\left(\mathrm{~m}, 4 \mathrm{H}, \mathrm{CH}_{2}\right) ;{ }^{13} \mathrm{C}$ NMR $\left(75 \mathrm{MHz}, \mathrm{CDCl}_{3}\right): \delta$ $167.2,157.6,142.6,140.6,135.7,131.6,128.9,126.4$, 120.8, 115.2, 71.9, 67.6, 50.9, 24.1; MS: $m / z\left(\mathrm{M}^{+}+\mathrm{H}\right) 382$. Anal. Calcd for $\mathrm{C}_{21} \mathrm{H}_{23} \mathrm{~N}_{3} \mathrm{O}_{4}$ : C, 66.13; H, 6.08; N, 11.02; Found: C, 65.89; H, 5.85; N,10.86.

$\left(3^{2} R, 3^{3} S\right)$-Phenyl-2 ${ }^{4}, 2^{5}, 3^{5}, 3^{6}$-tetrahydro- ${ }^{1} H, 3^{2} H, 6^{1}$ $H-4,11-d i o x a-6(5,1)$-triazola-2(3,5)-pyrazola-3(2, 3)-pyrane-1(1,2)-benzenacycloundechaphane (21)

A mixture of compound $20(0.200 \mathrm{~g}, 0.52 \mathrm{mmol})$, phenylhydrazine $(0.100 \mathrm{~g}, 0.92 \mathrm{mmol})$ and anhydrous sodium acetate $(0.100 \mathrm{~g}, 1.21 \mathrm{mmol})$ in glacial acetic acid $(20 \mathrm{~mL})$ was refluxed for $7 \mathrm{~h}$. Then the reaction mixture was concentrated in vacuo and cooled at room temperature, the solid thus separated was filtered, washed thoroughly with water, the unprocessed product thus obtained was purified by column chromatography on silica gel with hexane-ethyl acetate as eluent to afford pure compound $21(0.165 \mathrm{~g}, 0.33 \mathrm{mmol}, 64 \%)$. Mp 219-221 ${ }^{\circ} \mathrm{C} .{ }^{1} \mathrm{H}$ NMR $\left(300 \mathrm{MHz}, \mathrm{CDCl}_{3}\right): \delta 8.16(\mathrm{~s}, 1 \mathrm{H}, \mathrm{ArH}), 7.67-7.49(\mathrm{~m}$, 4H, ArH), 7.28-7.24 (m, 5H, ArH), 5.80-5.72 (m, 2H, $=\mathrm{CH}), 4.69\left(\mathrm{~s}, 2 \mathrm{H}, \mathrm{CH}_{2}\right), 3.99-3.94\left(\mathrm{~m}, 6 \mathrm{H}, \mathrm{CH}_{2}\right), 3.84$ $3.80(\mathrm{~m}, 2 \mathrm{H}, \mathrm{CH}), 2.89(\mathrm{~m}, 1 \mathrm{H}, \mathrm{CH}), 1.84-1.78(\mathrm{~m}, 6 \mathrm{H}$, $\left.\mathrm{CH}_{2}\right) ;{ }^{13} \mathrm{C} \mathrm{NMR}\left(75 \mathrm{MHz}, \mathrm{CDCl}_{3}\right): \delta 157.8,151.6,142.6$, $131.7,129.9,128.7,126.1,120.2,117.6,116.8,115.6$, 85.4, 74.1, 72.6, 66.1, 64.7, 51.2, 47.6, 32.6, 23.9; MS: $\mathrm{m} / \mathrm{z}\left(\mathrm{M}^{+}+\mathrm{Na}\right)$ 494. Anal. Calcd for $\mathrm{C}_{27} \mathrm{H}_{29} \mathrm{~N}_{5} \mathrm{O}_{3}: \mathrm{C}, 68.77$; H, 6.20; N, 14.85; Found: C, 68.59; H, 5.97; N, 14.51.

$\left(3^{2} R-3^{3} S\right)-2^{4}, 2^{5}, 3^{3}, 3^{6}$-Tetrahydro- $3^{2} H, 6^{1} H-4,11-$ dioxa$2(4,6)$-pyrimidina-6(5,1)-triazola-3 $(2,3)$-pyrana-1 $(1,2)$-benzenacycloundecaphane-2-amine (22) 
To aq. $\mathrm{NaOH}(0.020 \mathrm{~g}, 0.5 \mathrm{mmol})$ solution $(5 \mathrm{~mL})$ the solution of $20(0.050 \mathrm{~g}, 0.13 \mathrm{mmol})$ and guanidine hydrochloride $(0.030 \mathrm{~g}, 0.31 \mathrm{mmol})$ in ethanol $(20 \mathrm{~mL})$ was added. The reaction mixture was refluxed, TLC (EtOAc : petroleum ether, 2:1) showed that the reaction was completed after $6 \mathrm{~h}$. Then it was poured in cold $10 \% \mathrm{HCl}(50$ $\mathrm{mL}$ ) solution and the obtained precipitate was collected by filtration, washed with water until free from acid and recrystallized from toluene-ethanol $(3: 2)$ to give pure $\mathbf{2 2}$ as a brown solid (0.039 g, $0.08 \mathrm{mmol}, 68 \%)$. Mp 279-281 ${ }^{\circ} \mathrm{C} .{ }^{1} \mathrm{H}$ NMR (300 MHz, $\left.\mathrm{CDCl}_{3}\right): \delta 7.09$ (brs, $2 \mathrm{H}, \mathrm{NH}_{2}$ ), $8.02(\mathrm{~s}, 1 \mathrm{H}, \mathrm{ArH}), 7.10-6.88(\mathrm{~m}, 4 \mathrm{H}, \mathrm{ArH}), 5.82-5.74(\mathrm{~m}$, $2 \mathrm{H},=\mathrm{CH}), 4.69\left(\mathrm{~s}, 2 \mathrm{H}, \mathrm{CH}_{2}\right), 4.09-3.94\left(\mathrm{~m}, 6 \mathrm{H}, \mathrm{CH}_{2}\right)$, $3.74-3.70(\mathrm{~m}, 2 \mathrm{H}, \mathrm{CH}), 2.74(\mathrm{~m}, 1 \mathrm{H}, \mathrm{CH}), 1.78-1.74(\mathrm{~m}$, $\left.4 \mathrm{H}, \mathrm{CH}_{2}\right), 1.54\left(\mathrm{~m}, 2 \mathrm{H}, \mathrm{CH}_{2}\right) ;{ }^{13} \mathrm{C} \mathrm{NMR}\left(75 \mathrm{MHz}, \mathrm{CDCl}_{3}\right)$ : $\delta 164.9,165.0,154.9,142.6,128.4,126.7,120.4,112.6$, 81.6, 72.6, 66.7, 65.4, 50.9, 43.9, 31.6, 23.9; MS: $m / z$ $\left(\mathrm{M}^{+}+\mathrm{Na}\right)$ 445. Anal. Calcd for $\mathrm{C}_{22} \mathrm{H}_{26} \mathrm{~N}_{6} \mathrm{O}_{3}: \mathrm{C}, 62.54 ; \mathrm{H}$, 6.20 ; N, 19.89; Found: C, 62.29; H, 6.01; N, 19.61 .

$\left(3^{2} S, 3^{3} S\right)-2^{4}, 2^{5}, 3^{3}, 3^{6}-$ Tetrahydro- $3^{2} H, 6^{1} H-4,11-d i-$ oxa-2 $(3,5)$-isoxozola-6(5,1)-triazola-3( 2,3$)$-pyrana-1 (1,2)-benzacyclodecaphane (23)

Mixture of compound $20(0.050 \mathrm{~g}, 0.13 \mathrm{mmol})$, hydroxylamine hydrochloride $(0.050 \mathrm{~g}, 0.71 \mathrm{mmol})$ and sodium acetate $(0.010 \mathrm{~g}, 0.12 \mathrm{mmol})$ in anhydrous glacial acetic acid $(20 \mathrm{~mL})$ was refluxed for about $8 \mathrm{~h}$. The reaction mixture was concentrated in vacuo and then poured into ice cold water, the solid thus separated was filtered off and washed with water and crystallized from ethanol to afford pure $23(0.031 \mathrm{~g}, 0.08 \mathrm{mmol}, 61 \%)$ as a brown solid. $\mathrm{Mp}$ 279-282 ${ }^{\circ} \mathrm{C} .{ }^{1} \mathrm{H}$ NMR $\left(300 \mathrm{MHz}, \mathrm{CDCl}_{3}\right): \delta 8.14(\mathrm{~s}, 1 \mathrm{H}$, ArH), 7.67-6.98 (m, 4H, ArH), 5.64-5.55 (m, 2H, =CH), $4.68\left(\mathrm{~s}, 2 \mathrm{H}, \mathrm{CH}_{2}\right), 4.09-3.96\left(\mathrm{~m}, 6 \mathrm{H}, \mathrm{CH}_{2}\right), 3.5(\mathrm{~m}, 1 \mathrm{H}$, $\mathrm{CH}), 3.87-3.85(\mathrm{~m}, 2 \mathrm{H}, \mathrm{CH}), 3.04\left(\mathrm{~m}, 2 \mathrm{H}, \mathrm{CH}_{2}\right), 1.79$ $1.66\left(\mathrm{~m}, 4 \mathrm{H}, \mathrm{CH}_{2}\right) ;{ }^{13} \mathrm{C}$ NMR $\left(75 \mathrm{MHz}, \mathrm{CDCl}_{3}\right): \delta 157.8$, $156.4,142.9,131.7,129.6,128.4,125.4,120.6,117.6$, 114.6, 82.6, 72.6, 65.4, 64.2, 63.2, 50.8, 35.9, 23.9; MS: $m / z\left(\mathrm{M}^{+}+\mathrm{H}\right)$ 397. Anal. Calcd for $\mathrm{C}_{21} \mathrm{H}_{24} \mathrm{~N}_{4} \mathrm{O}_{4}$ : C, 63.62; H, 6.10; N, 14.13; Found: C, 63.39; H, 5.87; N, 13.91 .

\section{Conclusions}

A series of novel furanose and pyranose macrocyclic enone heterocycles was prepared and evaluated for their anticancer activity. Among the tested compounds $\mathbf{9}$ and $\mathbf{2 3}$ showed the most potent activity against MCF-7 cell line with $\mathrm{IC}_{50}$ value of 1.82 and $1.90 \mu \mathrm{M}$, whereas 10, 11, 21 and $\mathbf{2 2}$ showed promising activity against MDA-MB-231 and HeLa cell lines.

\section{Acknowledgements}

The authors are thankful to CSIR-New Delhi for the financial support (Project funding No 02/247/15/EMR-II),
Director, CSIR- IICT, Hyderabad, India, for NMR and MS spectral analysis and Shanthi Research foundation for their moral support.

\section{Reference}

1. (a) A. Farran, C. Cai, M. Sandoval, Chem. Rev. 2015, 115, 6811-6853. DOI:10.1021/cr500719h

(b) A. Varki, Glycobiology 1993, 3, 97-130.

DOI:10.1093/glycob/3.2.97

2. N. Galonde, K. Nott, A. Debuigne, J. Chem. Tech. Biotechnol. 2012, 87, 451-471. DOI:10.1002/jctb.3745

3. (a) M. E. Caines, H. Zhu, M. Vuckovic, J. Bio. Chem. 2008, 283, 31279-31283. DOI:10.1074/jbc.C800150200

(b) H. Shirato, S. Ogawa, H. Ito, J. Virol. 2008, 82, 1075610767. DOI:10.1128/JVI.00802-08

(c) S. Nagaraj, K. Gupta, V. Pisarev, Nat. Med. 2007, 13, 828-

835. DOI:10.1038/nm1609

4. (a) C. R. Bertozzi, L. L. Kiessling, Chem. Glyc. Bio. Sci. 2001, 291, 2357-2364. DOI:10.1126/science.1059820

(b) T. Angata, A. Varki, Chem. Rev. 2002, 102, 439-470. DOI: $10.1021 / \mathrm{cr} 000407 \mathrm{~m}$

5. (a) V. K. Tiwari, R. C. Mishra, A. Sharma, R. P. Tripathi, Mini Rev. Med. Chem. 2012, 12, 1497-1519.

DOI:10.2174/138955712803832654

(b) V. K. Tiwari, B. B. Mishra, K. B. Mishra, N. Mishra, A. S. Singh, Chen, Chem. Rev. 2016, 116, 3086-3240.

DOI:10.1021/acs.chemrev.5b00408

(c) K. B. Mishra, B. B. Mishra, V. K. Tiwari, Carbohyd. Res. 2014, 399, 2-7. DOI:10.1016/j.carres.2014.09.001

(d) D. Kumar, K. B. Mishra, B. B. Mishra, V. K.Tiwari, Steroids 2014, 80, 71-79. DOI:10.1016/j.steroids.2013.11.022

6. R. Huisgen, G. Szeimies, L. Moebius, Chem. Ber. 1967, 100, 2494-2507. DOI:10.1002/cber.19671000806

7. (a) F. G. Heras, R. Alonso, G. Alonso, J. Med. Chem. 1979, 22, 491-496. DOI:10.1021/jm00191a007

(b) J. C. Morris, J. Chiche, C. Grellier, J. Med. Chem. 2011, 54, 6905-6918. DOI:10.1021/jm200892s

8. (a) V. Balzani, A. Credi, F. M. Raymo, J. F. Stoddart, Angew. Chem. Int. Ed. 2000, 39, 3349-3391.

DOI:10.1002/1521-3773(20001002)39:19<3348::AID-ANIE 3348>3.0.CO;2-X

(b) C. P. Collier, G. Mattersteig, E. W. Wong, Y. Luo, K. Beverley, J. Sampaio, F. M. Raymo, J. F. Stoddart, J. R. Heath, Science 2000, 289, 1172-1175. DOI:10.1126/science.289.5482.1172

9. (a) E. M. Driggers, S. P. Hale, J. Lee, N. K. Terrett, Nat. Rev. Drug. Discov. 2008, 7, 608-624. DOI:10.1038/nrd2590

(b) D. B. Amabilino, J. F. Stoddart, Chem. Rev. 1995, 95, 2725-2828. DOI:10.1021/cr00040a005

(c) G. R. Pettit, Y. Kamano, C. L. Herald, J. Nat. Prod. 1986, 49, 661-664. DOI:10.1021/np50046a017

10. P. Corvalin, Antimicrob. Agents Chemother. 1990, 34, 22912296. DOI:10.1128/AAC.34.12.2291

11. (a) J. A. Wells, L. McClendon, Nature 2007, 450, 1001-1009. DOI:10.1038/nature06526 
(b) K. Ahsanullah, J. Rademann, Angew. Chem. Int. Ed. 2010, 49, 5378-5380. DOI:10.1021/jo2018203

12. (a) P. T. Quinn, P. D. Atwood, J. M. Tanski, T. F. Moore, F. Andersen, J. Org. Chem. 2011, 76, 10020-10030. (b) C. Nunez, A. Aldrey, V. García, R. Bastida, A. Macías, C. Lodeiro, Inorg. Chim. Acta. 2012, 381, 85-94. DOI:10.1016/j. ica.2011.05.031

13. (a) S. Camiolo, P. A. Gale, M. B. Hursthouse, M. E. Light, Org. Biomol. Chem. 2003, 1, 741-744. (b) C. Bazzicalupi, A. Bencini, I. Matera, S. Puccioni, B. Valtancoli, Inorg. Chim. Acta 2012, 381, 162-169. DOI:10.1016/j.ica.2011.08.057

14. (a) C. W. Tornoe, C. Christensen, M. Meldal, J. Org. Chem. 2002, 67, 3057-3064. DOI:10.1021/jo011148j

(b) M. Meldal, C. W. Tornoe, Chem. Rev. 2008, 108, 29523015. DOI: $10.1021 / \mathrm{cr} 0783479$

15. (a) Y. Hua, A. H. Flood, Chem. Soc. Rev. 2010, 39, 1262-1271. DOI:10.1039/b818033b

(b) Y. Li, A. H. Flood, Angew. Chem. Int. Ed. 2008, 47, 26492652. DOI:10.1002/anie.200704717

16. (a) H. C. Kolb, K. B. Sharpless, Drug Discovery Today 2003, 8 , 1128-1137. DOI:10.1016/S1359-6446(03)02933-7

(b) J. Campbell, H. E. Blackwell, J. Comb. Chem. 2009, 11, 1094-1099. DOI:10.1021/cc900115x

17. J. T. Desai, C. K. Desai, K. R. Desai, J. Iran. Chem. Soc. 2008, 5, 67-73. DOI:10.1007/BF03245817

18. D. Milicevic, R. Kimmel, D. Urankar, A. Pevec, J. Košmrlj, S. Kafka, Acta Chim. Slov. 2020, 67, 421-434.

19. A. R. Aghakand, K. A. Dilmaghani, Z. D. Ghezelbash, B. Asghari, Acta Chim. Slov. 2019, 66, 344-350.

DOI:10.17344/acsi.2018.4841

20. S. A. M. K. Nasser, Carbohydr. Res. 2006, 341, 2187-2199. DOI:10.1016/j.carres.2006.06.007

21. Y. C. Sung, H. A. Jin, D. H.Jae, K. K. Seung, Y. B. Ji, S. H.Sang, Y. S. Eun, S. K.Sang, R. K. Kwang, G. C. Hyae, K. C. Joong, Bull. Kor. Chem. Soc. 2003, 24, 1455-1459.

22. Y. S. Lee, S. M. Park, B. H. Kim, Bioorg. Med. Chem. Lett. 2009, 19, 1126-1128.

23. J. F. Hansen, S. A. Stronge, J. Heterocycl. Chem. 1977, 14, 1289-1294. DOI:10.1002/jhet.5570140734

24. T. K. Adhikari, A. Vasudeva, M. Girisha, Indian J. Chem. 2009, 48B, 430-437.

25. S. Balalie, A. Sharifi, A. Ahangarian, Indian J. Heterocycl. Chem. 2000, 10, 149-154.

26. H. Kai, T. Ichiba, M. Tomida, H. Nakai, K. Morita, J. Pest. Sci. 2000, 25, 267-273. DOI:10.1584/jpestics.25.267

27. V. V. Kachadia, M. R. Patel, S. H. Joshi, J. Sci. I. R. Iran 2004, $15,47-52$.

28. M. Marcin, Z. Machail, D. S. Eva, R. Stanislaw, Cell. Mol. Biol. Lett. 2005, 10, 613-619.

29. N. R. Nagar, V. H. Shan, Indian J. Heterocycl. Chem. 2003, 13, 173-179.

30. A. Srinivas, M. Sunitha, P. Karthik, G. Nikitha, K. Raju, B. Ravinder, S. Anusha, T. Rajasri, D. Swapna, D. Swaroopa, K. Srinivas, K. Vasumathi Reddy, J. Heterocycl. Chem. 2017, 54, 3250-3257. DOI:10.1002/jhet.2943

31. A. Srinivas, Acta Chim. Slov. 2016, 63,173-179.
32. A. Srinivas, M. Sunitha, Indian J. Chem. Sect. B 2016, 55B, 102-109.

33. A. Srinivas, M. Sunitha, Indian J. Chem. Sect. B 2016, 55B, 1239-1242.

34. C. S. Reddy, A. Srinivas, M. Sunitha, A. Nagaraj, J. Heterocycl. Chem. 2010, 47, 1303-1309. DOI:10.1002/jhet.474

35. A. Srinivas, C. S. Reddy, A. Nagaraj, Chem. Pharm. Bull. 2009, 57, 685-693.

36. C. S. Reddy, A. Srinivas, A.Nagaraj, J. Heterocycl. Chem. 2009, 46, 497-502. DOI:10.1002/jhet.100

37. C. S. Reddy, A.Srinivas, A. Nagaraj, J. Heterocycl. Chem. 2008, 45, 1121-1125. DOI:10.1002/jhet.5570450428

38. C. S. Reddy, A. Srinivas, A. Nagaraj, J. Heterocycl. Chem. 2008, 45, 999-1003. DOI:10.1002/jhet.5570450409

39. K. Y. Lee, J. M. Kim, J. N. Kim, Tetrahedron Lett. 2003, 44, 6737-6740. DOI:10.1016/S0040-4039(03)01648-4

40. P. Erhan, A. Mutlu, U. Tayfun, E. Dilek, Eur. J. Med. Chem. 2001, 36, 539-543. DOI:10.1016/S0223-5234(01)01243-0

41. R. A. Nugen, M. Meghan, J. Med. Chem. 1993, 36, 134-139.

42. H. Kawazura, Y. Takahashi, Y. Shiga, F. Shimada, N. Ohto, A. Tamura, Jpn. J. Pharmacology 1997, 73, 317-324.

DOI:10.1254/jjp.60.317

43. M. J. Genin, C. Bilers, B. J. Kieser, S. M. Poppe, S. M. Swaney, W. G. Tarpley, Y. Yagi, D. L. Romero, J. Med. Chem. 2000, 43, 1034-1040. DOI:10.1021/jm990383f

44. A. G. Habeb, P. N. P. Rao, E. E. Knaus, J. Med. Chem. 2001, 44, 3039-3042. DOI:10.1021/jm010153c

45. H. Hashimoto, K. Imamura, J. I. Haruta, K. Wakitani, J. Med. Chem. 2002, 45, 1511-1517. DOI:10.1021/jm010484p

46. M. Sakya, B. Rast, Tetrahedron Lett. 2003, 44, 7629-7632. DOI:10.1016/j.tetlet.2003.08.054

47. L. David, D. G. B. Selwood, J. Med. Chem. 2001, 44, 78-93.

48. J. M. Parmar, J. J. Modha, A. R. Parikh, Indian J. Chem. 1999, 38B, 440-444.

49. V. K. Ahluwalia, B. Madhu, Indian J. Chem. 1996, 35B, 742746.

50. (a) K. S. Atwal, G. C. Roynyk, S. D. Kimball, D. M. Floyd, S. Moreland, J. Med. Chem. 1990, 33, 2629-2635.

DOI:10.1021/jm00171a044

(b) K. S. Atwal, B. N. Swanson, S. E. Unger, D. M. Floyed, S. Moreland, A. Hedberg, B. C. Orielly, J. E. T. Corrie, J. Med. Chem. 1991, 34, 806-811. DOI:10.1021/jm00106a048

(c) G. C. Rovnyk, K. S. Atwal, S. D. Kimball, J. Med. Chem. 1992, 35, 3254-3263. DOI:10.1021/jm00095a023

(d) G. C. Rovnyk, S. D. Kimball, B. Beyer, G. Cucinotta, J. D. Dimorco, J. Gougoutas, A. Hedberg, M. Molley, J. P. McCarthy, R. Zhang, S. Moreland, J. Med. Chem. 1995, 38, 119-129. DOI:10.1021/jm00001a017

51. V. K. Ahluwalia, M. Bala, Indian J. Chem. 1996, 35B, 742-748.

52. S. Kothari, R.Vyas, B. L. Verma, Indian J. Heterocycl. Chem. 1999, 8, 285-291.

53. S. Purushotham, R. Prasanna, R. Raghunathan, Tetrahedron 2013, 69, 9742-9750. DOI:10.1016/j.tet.2013.09.015

54. C. K. Chu, J. W. Beach, G. V. Ullas, Y. Kosugi, Tetrahedron Lett. 1988, 29, 5349-5352.

DOI:10.1016/S0040-4039(00)82864-6 


\section{Povzetek}

Iz alkil etrov in triazolov kot distančnikov smo s kombinacijo klik reakcije in intramolekularne aldolne kondenzacije uspešno izvedli sintezo makrocikličnih enonov. Nove makrociklične enone smo uspešno uporabili tudi kot dipolarofile v 1,3-dipolarnih cikloadicijah. Dipole smo pripravili iz hidrazin hidroklorida, hidroksilamina in gvanidin hidroklorida ter jih reagirali $\mathrm{z}$ makrocikličnimi enoni; te reakcije so $\mathrm{z}$ dobrimi izkoristki vodile do nastanka novih spiro makrociklov substituiranih $\mathrm{z}$ aminopirimidini, fenil pirazoli in izoksazoli. Strukture novih produktov smo potrdili z IR, NMR in masno spektrometrijo ter določili njihovo aktivnost proti rakastim celicam. 